\title{
The extended pterional approach allows excellent results for removal of anterior cranial fossa meningiomas
}

\author{
0 acesso pterional extendido permite excelente resultado para a ressecção dos \\ meningiomas da fossa craniana anterior \\ Jose Carlos Lynch'1, Mariangela Barbi Gonçalves', Celestino Esteves Pereira², Wladimir Melo², Gianni \\ Ferraz Temponi
}

\begin{abstract}
Objective: To describe a unique operative strategy, instead the classical pterional approach, and to analyses it safety and effectiveness for removal of anterior cranial fossa meningiomas. Method: We identify 38 patients with tuberculum sellae and olphactory groove meningiomas operated between 1986 and 2013. Medical charts, operative reports, imaging studies and clinical follow-up evaluations were reviewed and analyzed retrospectively. The pterional craniotomy is extended toward the frontal bone providing access through the subfrontal route, besides the usual anterolateral view provided by the classical pterional approach. Results: Surgical mortality occurred in one patient (2.6\%). Gross total resection was achieved in 27 patients (86.8\%). Median time of follow-up was 69.4 months. Conclusion: The extended pterional approach allows excellent results. Total removal of meningiomas of the anterior cranial fossa was obtained in $86.8 \%$ of patients, with low morbidity and mortality.
\end{abstract}

Keywords: meningiomas; cranal fossa, anterior; microsurgery.

RESUMO

Objetivo: Descrever a craniotomia pterional estendida, ao invés da abordagem pterional clássica, e analisar sua segurança e eficácia para a remoção dos meningiomas da fossa anterior. Método: Identificamos 38 pacientes com meningiomas do tubérculo da sela e da goteira olfatória operados entre 1986 e 2013. Os prontuários, relatórios cirúrgicos, exames de imagem e acompanhamento pós-operatório foram analisados retrospectivamente. A craniotomia pterional com extensão para o osso frontal permite acesso pela via subfrontal além da via anterolateral do acesso pterional clássico. Resultados: A mortalidade cirúrgica foi de 2,6\% (um paciente). A remoção total foi alcançada em $86,8 \%$ (27 pacientes) com um tempo médio de seguimento de 69,4 meses. Conclusão: A abordagem pterional estendida permite excelentes resultados. A remoção total dos meningiomas da fossa craniana anterior foi obtida em $86,8 \%$ dos pacientes, com baixa morbi-mortalidade.

Palavras-chave: meningiomas; fossa cranial anterior; microcirurgia.

Olfactory groove meningiomas (OGMs) and tuberculum sellae meningiomas (TSMs) arise both in the anterior cranial fossa. OGMs are a subset of meningiomas that grows over the cribiform plate and the frontosphenoidal suture. They represent $8-18 \%$ of all intracranial meningiomas ${ }^{1,2,3,45}$. OGMs displace the optic nerve $(\mathrm{ON})$ and the chiasm inferiorly and posteriorly. TSMs originate from the limbus sphenoidale, chiasmatic sulcus and frontosphenoidal suture. They comprise 3 to $12 \%$ of all intracranial meningiomas ${ }^{1,6,7,8,9,10,11}$. TSMs displace the ON superiorly and laterally and the chiasm superiorly and posteriorly $y^{6,12,13,14,15}$.
The distance between the tuberculum sellae and the cribiform plate is a scanty $2 \mathrm{~cm}^{1}$. Nonetheless, OGMs and TSMs have features in common, mainly in cases of large meningiomas with invasion of the surrounding structures. On the basis of preoperative imaging studies and intraoperative inspection, it is often difficult to determine the exact origin of the meningioma ${ }^{13,6,8,10,11,13,14,15,16}$ (Figures 1, 2, 3, 4).

Despite the advances of microsurgery, the management of anterior fossa meningiomas remains a great challenge. Since these tumors grew in close contact with neural and vascular structures that cannot be sacrificed or retracted, they still

${ }^{1}$ Rede D’Or São Luiz, Rio de Janeiro RJ, Brasil;

${ }^{2}$ Hospital Federal dos Servidores do Estado do Rio de Janeiro, Serviço de Neurocirugia, Rio de Janeiro RJ, Brasil.

Correspondence: José Carlos Lynch; Rua Jardim Botânico, 600/605; 22461-000 Rio de Janeiro RJ, Brasil; E-mail: cneuroamericas@uol.com.br

Conflict of interest: There is no conflict of interest to declare.

Received 21 October 2015; Accepted 09 December 2015. 

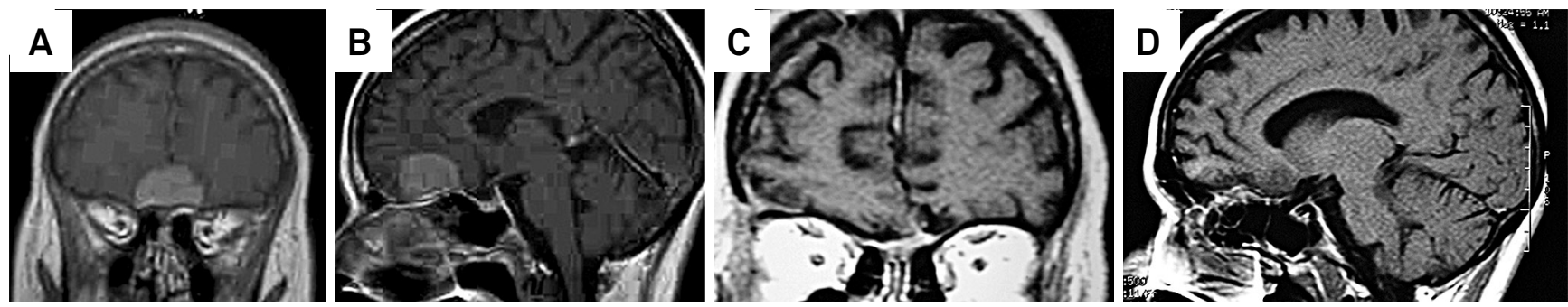

Figure 1. Preoperative gadolinium-enhanced T1-weighted coronal (A) and sagittal (B) MRI demonstrating a large OGM in a 44-year-old woman with progressive decrease of visual function. Postoperative coronal (C) and sagittal (D) T1-weighted contrast-enhanced MRI demonstrating GTR.

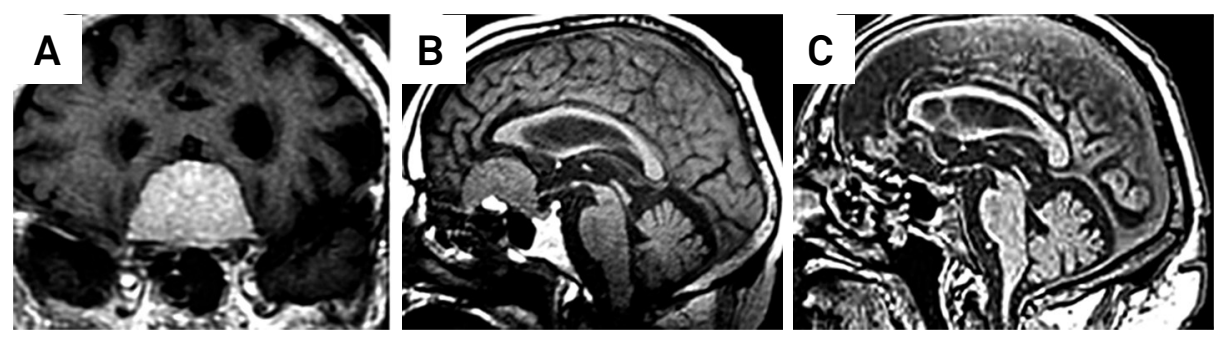

Figure 2. Preoperative coronal (A) and sagittal (B) gadolinium-enhanced T1-weighted MRI revealed a large bilateral OGM in a 71-years old man with mood alterations and progressive apathy. Postoperative sagittal (C) gadolinium-enhance T1- weighted MRI, confirming GTR obtained through a right pterional approach.

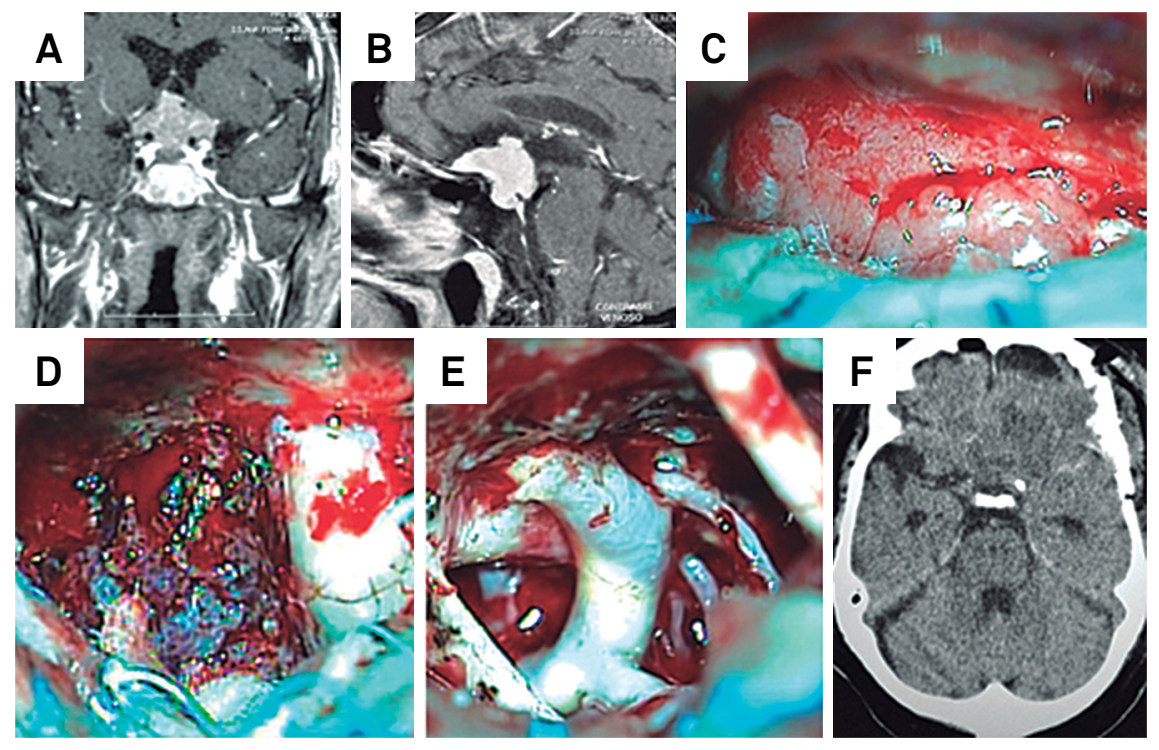

Figure 3. Preoperative coronal (A) and sagittal (B) gadolinium-enhanced T1-weighted MRI revealed a TSM. Intraoperative images (C). Following dissection of the arachnoid, the tumor is clearly seen in the tuberculum sellae. After removal of the suprasellar portion, the meningioma is identified medially to the right ON (D). After GTR, the opposite internal carotid artery, posterior communicating artery and carotid artery bifurcation are completely exposed (E). Early postoperative images showing GTR (F).
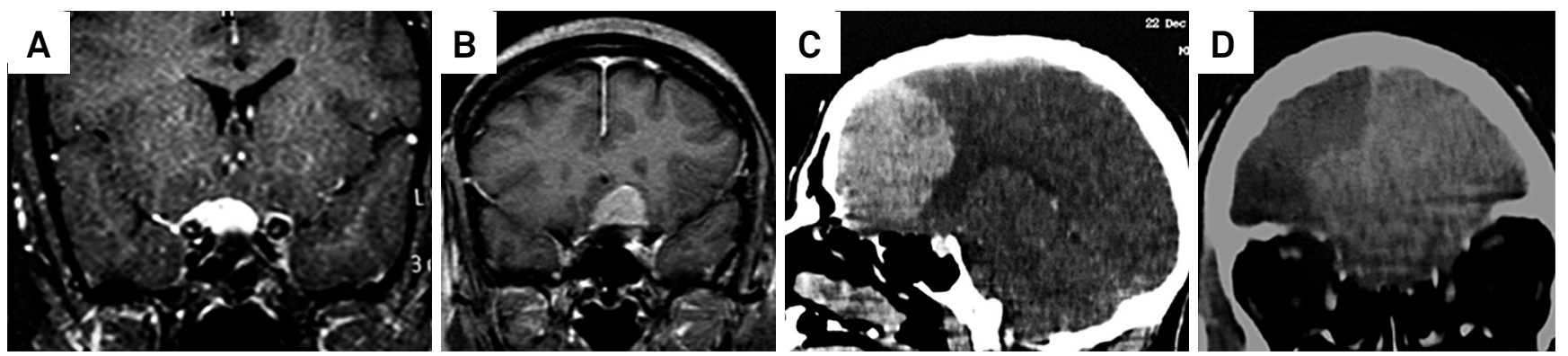

Figure 4. T1-weighted MRI with contrast enhancement in cases of A: small, B: medium, C: large: and D: giant OGMs and TSMs. 
raise controversies related to the best surgical approaches to deal with these lesions ${ }^{1,5,8,10,11,12,13,14,15,16,17,18,19,20,21,22,23,24,25}$.

In our study, we describe a unique operative strategy and personal nuances of the microsurgical technique. We also emphasize the surgical results and discuss the best operative approach in dealing with such challenging lesions.

\section{METHOD}

\section{Data collection}

Thirty-eight patients with anterior fossa meningiomas underwent surgery through the extended pterional trans-sylvian approach, performed mainly by the senior author (JCL), between 1986 and 2013. The demographic and clinical profiles of the patients are summarized in Tables 1 and 2 respectively. Duration of symptoms ranged from 3 to 120 months (mean, 12 months). The intraoperative videos and photos of 27 patients were retrospectively analyzed for nuances of the microsurgical technique. The Simpson grade of meningioma resection was determined through review of the operative report, surgeon's assessment and postoperative images. Pathological review was performed based on the World Health Organization (WHO) guidelines. The need for informed consent was waived due to the retrospective character of the study.

\section{Tumor characteristics}

As depicted from preoperative MRI scans and confirmed during surgery, meningiomas located in the anterior fossa were classified into two subgroups according to their dural attachment. Tumors attached to the cribiform plate and to the frontosphenoidal suture were classified as olfactory groove meningiomas. Those attached to the limbus sphenoidale, chiasmatic sulcus and frontosphenoidal suture were classified as tubercullum sellae meningiomas. We also classified

Table 1. Demographic characteristics of the study population.

\begin{tabular}{lcc}
\hline Characteristic & Number & Percentage \\
\hline Age & & \\
7 to 84 years & 38 & 100 \\
Median (range) & 54.5 years & - \\
Gender & & \\
Females & 22 & 57.6 \\
Males & 16 & 42.4 \\
\hline
\end{tabular}

Table 2. Clinical presentation.

\begin{tabular}{lcc}
\hline Symptoms & Number & Percentage \\
\hline Personality changes & 28 & 73.4 \\
Headache & 14 & 36.8 \\
Seizure & 6 & 18.1 \\
Visual deficit & 9 & 13.2 \\
Obesity & 3 & 7.8 \\
\hline
\end{tabular}

anterior fossa meningiomas according to their size as giant (> $6 \mathrm{~cm})$, large $(4-6 \mathrm{~cm})$, medium $(2-4 \mathrm{~cm})$ and small $(<2 \mathrm{~cm})$.

\section{Surgical approach and microsurgical technique}

Patients underwent surgery according to the technique described by Yasargil in 1975 with the following modifications: a pterional craniotomy with extension toward the frontal bone providing access through the subfrontal route, besides the usual anterolateral view provided by the classical pterional approach. Craniotomy is performed from the frontal bone to the ipsilateral supraorbital prominence, avoiding the frontal sinus. The frontotemporal duramater is opened in a curvilinear fashion over the Sylvian fissure and a second incision is directed toward the falciform ligament. The extended pterional approach described above was used in all cases.

\section{OGMs}

The progressive elevation of the tumor from the cribiform plate and planum sphenoidale reveals small arteries that irrigate the meningioma. In order to decrease intraoperative bleeding, early interception of these feeding arteries is essential. The tumor capsule is bipolar coagulated medial to the ipsilateral $\mathrm{ON}$ and the tumor is debulked. If dissection of the tumor from the perforators is tenacious, it is better to leave a shell of the tumor on the vessel wall than to risk the rupture of the artery. The basal dura with tumor invasion is bipolar coagulated and striped off, and the underline hypertrophic bone is partially drilled away without entering the sphenoidal sinus (Simpson Grade 2).

\section{TSMs}

The dissection must start in the planum sphenoidale or tuberculum sellae, bipolar coagulating the feeding arteries. Internal tumor debulking is achieved by piecemeal resection. The tumor located posterolaterally to the $\mathrm{ON}$ and medial to the internal carotid artery is carefully dissected through the optic carotid triangle and removed from beneath the ON. A diamond ball must be used for drilling the roof of the optic canal when the tumor extends through it. Copious irrigation is mandatory to prevent damage to the $\mathrm{ON}$ by the heat. The meningioma is exposed and carefully dissected from the inferior and medial aspect of the ON with minimal manipulation.

\section{Patients Follow-up}

In the immediate postoperative period, patients were submitted to contrast-enhanced computed tomography scans. All patients were followed up with Magnetic Resonance Imaging (MRI) studies 3 and 12 months after surgery. The mean follow-up period was 69,4 months (range, 4-324 months). Thereafter, patients were reexamined or at least interviewed by telephone. The Glasgow Outcome Scale (GOS) defined the outcome (Table 3). 


\section{RESULTS}

Tumor size, histological subtype and location are summarized in Table 4.

Operative mortality was $2.6 \%$ (one patient) due to a pulmonary thromboembolism 15 days after discharged from hospital. A 77 years-old female died 3 months after surgery due to an acute subdural hematoma. One patient died 18 months after discharged from hospital because of a pulmonary carcinoma. Other patient affected by obesity and cardiac failure died 2 years after the operation. Excellent or good outcome (GOS 4 or 5) was achieved in 31 patients (81,5\%). There were 2 patients with postoperative Cerebro Spinal Fluid (CSF) leakage who returned to the operating room for repair. Surgical outcome and follow up are summarized in Table 3.

Table 3. Surgical outcome and follow-up.

\begin{tabular}{lcc}
\hline & Number & Percentage \\
\hline GTR & 33 & 86 \\
Mortality & 1 & 2.6 \\
Complications & & \\
Seizures & 3 & 7.8 \\
CSF leak & 2 & 5.2 \\
Meningitis & 2 & 5.2 \\
Recurrence & 2 & 5.2 \\
GOS & & \\
1 & 4 & 10.5 \\
3 & 3 & 7.9 \\
4 & 8 & 21.1 \\
5 & 23 & 60.5 \\
\hline
\end{tabular}

GTR: Gross total resection;CSF: Cerebrospinal flud; GOS: Glasgow Outcome Scale.

Table 4. Tumor characteristics.

\begin{tabular}{lcc}
\hline Characteristic & Number & Percentage \\
\hline WHO & 38 & 100 \\
Meningioma grade 1 & & \\
Histological type & 25 & 65.7 \\
$\quad$ meningotheliomatous & 7 & 18 \\
fibroblastic & 3 & 7.8 \\
psammomatous & 2 & 5.2 \\
transitional & 1 & 2.6 \\
angioblastic & & \\
Size & 5 & 13.1 \\
Small & 15 & 39.4 \\
Medium & 13 & 34 \\
Large & 5 & 13.15 \\
Giant & & \\
Location & 30 & 78.9 \\
Olfactory groove & 8 & 21.1 \\
Tuberculum selae & & \\
\hline WHO:World Health Organization. &
\end{tabular}

\section{DISCUSSION}

\section{Surgical approaches and microsurgical techniques}

Various approaches have been described in the literature to treat anterior fossa meningiomas, including the pterion$\mathrm{al}^{1,7,10,11,13,17,20,22,26}$, uni ${ }^{3,5,17,23,24}$ or bilateral subfrontal ${ }^{8,11,21,27}$ and cranial base approaches ${ }^{9,2,5,16,25,27}$. The surgical technique presented here is modified from one described earlier by Yasargil and others ${ }^{1,7,10,11}$.

The extended pterional approach has a number of advantages over the bifrontal craniotomy: provides the shortest distance to the tuberculum sellae, the early release of CSF from the basal cisterns, allows brain relaxation and minimizes frontal lobe retraction. Early exposure of the $\mathrm{ON}$ and chiasm provides protection of the visual system. The identification of the internal carotid artery improves the ability to dissect the anterior cerebral artery and its branches, allowing protection of these vessels $1,7,10,11,13,14,17,19,20,22,26,28,29,30$.

The disadvantage of the pterional approach is the inadequate visualization of the undersurface of the ipsilateral $\mathrm{ON}$ and chiasm. However we can circumvent this problem by moving the surgical microscope medially, associated with lateral tilt of the operative table. This surgical nuances technique was not published before.

Nakamura et al. ${ }^{11}$ compared the results of their patients operated via bifrontal and frontolateral approaches. They claimed that the frontolateral and pterional approaches provide remarkable improvement compared with the bifrontal approach. To decrease tumor recurrence, some authors recommend cranial base approaches such as uni or bilateral orbital osteotomy and cranial base drilling and reconstruction ${ }^{2,5,8,16,25}$.

The demographic characteristics of the patients in this series did not influence the results.

\section{Extend of resection and recurrence}

Gross total resection (GTR) was accomplished by a complete macroscopic lesion removal and coagulation of its dural attachment (Simpson grade II) in $33(86,8 \%)$ patients and subtotal resection in 5 (13.1\%). Published papers on TSMs and OGMs have reported GTR rates ranging from $71 \%$ to $100 \%$ (Table 2). Some surgeons stated that Simpson Grade I resection including dural attachment and underlying tumor-infiltrated bone is critical in preventing future recurrence. ${ }^{25}$ Nevertheless, several surgeons, including the authors of the current paper, have preferred a more conservative approach, not entering the paranasal sinuses, because of the risk of postoperative CSF leakage and infection, especially in elderly patients ${ }^{4,9,10,11,13,17,18,20,21,22,23}$. In published microsurgical series, the recurrence rate for TSMs and OGMs, with a follow-up period ranging from 2 to 9.3 years, varies from 0 to $41 \%{ }^{5,10,13,16}$ The recurrence rate of this sample, with a median follow-up of 5.7 years (range 4-324 months), was 5.2\%. 


\section{Mortality and clinical outcome}

Cushing $^{6}$ reported an operative mortality of $27.5 \%$. As a result of the refinements of microsurgical techniques, death rates had declined ${ }^{11,18,20,23,26,29}$. In this present series, the surgical mortality occured in one patient (2.6\%), with $31(81.5 \%)$ patients obtaining GOS 4 or 5 . Al-Mefty ${ }^{25}$ and Solero et al. ${ }^{1}$ observed higher mortality rates in patients with tumors exceeding $3 \mathrm{~cm}$ in diameter, compared with mortality rates in patients with smaller tumors. In our series, 18 individuals (47.36\%) harbored large or giant tumors, but we did not observed increase in mortality in this group of patients.

Nowadays, the preservation of vision is an important goal of treatment. Fahlbusch and Schott ${ }^{10}$ and Symon ${ }^{18}$ found tumors smaller than $3 \mathrm{~cm}$ to be associated with better visual outcomes than tumors larger than $3 \mathrm{~cm}$ in diameter. In this sample, improvement of vision occured in $10.5 \%$ of patients and preserved vision with no further deterioration in $89.4 \%$. Improvement or stabilization of vision has been reported in 48.8 to $100 \%$ of patients undergoing surgery (Table 5).

We can conclude that the extended pterional transsylvian approach has many advantages. It is simple and fast, while preserving normal anatomy. The early exposure of the $\mathrm{ON}$ and chiasm provides protection of the visual system. In this paper we show that we can achieve a low mortality and morbidity, with a high rate of GTR, fewer complications, and low recurrence rates with the extended pterional transsylvian approach. Our study confirms that the pterional approach and its variants are effective to remove anterior fossa meningiomas.

Table 5. Microsurgical series for TSM and OGM.

\begin{tabular}{|c|c|c|c|c|c|c|}
\hline Authors & No Patients & Mortality (\%) & Visual Improvement/STB (\%) & GTR (\%) & Recurrence (\%) & Years of $F / U$ \\
\hline Symon and Rosentein ${ }^{18} / 1977$ & 33 & 3 & $\mathrm{~N} / \mathrm{A}$ & 82 & 3.1 & $\mathrm{~N} / \mathrm{A}$ \\
\hline Solero et al. ${ }^{4} / 1983$ & 55 & 2.3 & 60 & 78 & 3 & $\mathrm{~N} / \mathrm{A}$ \\
\hline Ojemann²1 / 1991 & 14 & 0 & 73 & 71 & $\mathrm{~N} / \mathrm{A}$ & $\mathrm{N} / \mathrm{A}$ \\
\hline Al-Mefty²5 / 1993 & 35 & 8.6 & 25 & 91 & $\mathrm{~N} / \mathrm{A}$ & $\mathrm{N} / \mathrm{A}$ \\
\hline Turazzi et al. ${ }^{20} / 1999$ & 37 & 2.7 & 100 & 100 & 0 & 4 \\
\hline Zeugaridis et al./ 2001 & 62 & 3.2 & 65 & $\mathrm{~N} / \mathrm{A}$ & N/A & 5.2 \\
\hline Fahlbusch and Schott ${ }^{6} / 2002$ & 47 & 0 & 80 & 98 & 4.2 & $N / A$ \\
\hline Jallo and Benjamim ${ }^{13} / 2002$ & 23 & 8.6 & 55 & 86.9 & 4.5 & 93 \\
\hline Goel et al. ${ }^{23} / 2002$ & 70 & 2.8 & $\mathrm{~N} / \mathrm{A}$ & 84 & 1.4 & $\mathrm{~N} / \mathrm{A}$ \\
\hline Hentschels and Demonte ${ }^{16} / 2003$ & 13 & 0 & 92.3 & 85 & 0 & 2 \\
\hline Colli et al. ${ }^{8} / 2007$ & 17 & 11.8 & $\mathrm{~N} / \mathrm{A}$ & 94.1 & 0 & 4.2 \\
\hline Bassioni et al. ${ }^{29} / 2007$ & 55 & 0 & 83.3 & 100 & 8.9 & $\mathrm{~N} / \mathrm{A}$ \\
\hline Romani et al.19 / 2009 & 65 & 0 & 21.4 & 91 & 9 & 3.7 \\
\hline Lynch et al. / 2015 & 38 & 2.6 & 89.4 & 86 & 5.2 & 5.7 \\
\hline
\end{tabular}

TSM:Tuberculum Sellae meningiomas; OGM: Olfactory groove meningiomas.

\section{References}

1. Solero CL, Giombini S, Morello G. Suprasellar and olfactory meningiomas: report on a series of 153 personal cases. Acta Neurochir (Wien). 1983;67(3-4):181-94. doi:10.1007/BF01401420

2. Colli BO, Carlotti CG Jr, Assirati JA Jr, Santos MB, Neder L, Santos $A C$ et al. Olfactory groove meningiomas: Surgical technique and follow-up review. Arq Neuropsquiatr. 2007;65(3B):795-9. doi:10.1590/S0004-282X2007000500012

3. Tella Jr OI, Paiva Neto MA, Herculano MA, Faedo Neto A. [Olfactory groove meningioma]. Arq Neuropsiquiatr. 2006;64(1):83-7. Portuguese. doi:10.1590/S0004-282X2006000100017.

4. Coppens JR, Couldwell WT. Olfactory groove meningiomas. In: Pamir MN, Black PM, Fahlbush R, editors. Meningiomas: a comprehensive text. New York: Saunders; 2009. p. 373-86.

5. Fox F, Khurana VG, Spetzler RF. Olfactory groove/planum sphenoidale meningiomas. In: Lee JH, editor. Meningiomas: diagnosis, treatment, and outcome, New York: Springer; 2008. p. 327-32.

6. Cushing $\mathrm{H}$, Eisenhardt L. Meningiomas: their classification, regional behavior, life history, and surgical end results. Baltimore: Charles C. Thomas; 1938. p. 224-283.

7. Yasargil MG: General operative techniques. In: Yasargil MG, editor. Microneurosurgery. Vol. 1: Microsurgical Anatomy of the basal cisterns and vessels of the brain, diagnostic studies, general operative techniques and pathological considerations of the intracranial aneurysms. New York: Georg Thieme/Thieme-Stratton; 1984. p. 208-33.

8. McDermott MW, Rootman J, Durity FA. Subperiosteal, subperiorbital dissection and division of the anterior and posterior ethmoid arteries for meningiomas of the cribriform plate and planum sphenoidale: technical note. Neurosurgery. 1995;36(6):1215-9. doi:10.1227/00006123-199506000-00027

9. Mathieson T, Lindqvist C, Kihlström, Karlsson B. Recurrence of cranial base meningiomas. Neurosurgery. 1996;39(1):2-7. doi:10.1097/00006123-199607000-00002

10. Fahlbusch R, Schott W. Pterional surgery of meningiomas of the tuberculum sellae and planum sphenoidale: surgical results with special consideration of ophthalmological and endocrinological outcomes. J Neurosurg. 2002;96(2):235-43. doi:10.3171/jns.2002.96.2.0235

11. Nakamura M, Struck M, Roser F, Vorkapic P, Samii M: Olfactory groove meningiomas: clinical outcome and recurrence rates after tumor removal through the frontolateral and bifrontal approach. Neurosurgery. 2008;62(6 Suppl 3):1224-32. 
12. Kempe LG: Olfactory groove meningioma. In: Kempe LG, editor. Operative neurosurgery. Vol 1: Cranial, cerebral, and intracranial vascular disease. New York:, Springer; 1968. p. 104-8.

13. Jallo GI, Benjamin V. Tuberculum sellae meningiomas: microsurgical anatomy and surgical technique. Neurosurgery. 2002;51(6):1432-40. doi:10.1097/00006123-200212000-00013

14. Spektor S, Valarezo J, Fliss DM, Gil Z, Cohen J, Goldman $\checkmark$ et al. Olfactory groove meningiomas from neurosurgical and ear, nose, and throat perspectives: approaches, techniques, and outcomes. Neurosurgery. 2005;57(4 Suppl): 268-80. doi:10.1227/01.NEU.0000176409.70668.EB

15. Zevgaridis D, Medele RJ, Müller A, Hischa AC, Steiger HJ. Meningiomas of the sellar region presenting with visual impairment: impact of various prognostic factors on surgical outcome in 62 patients. Acta Neurochir (Wien). 2001;143(5):471-6. doi:10.1007/s007010170076

16. Hentschel SJ, DeMonte F. Olfactory groove meningiomas. Neurosurg Focus. 2003;14(6):e4.

17. Aguiar PH, Tahara A, Almeida AN, Simm R, Silva AN, Maldaun MV et al. Olfactory groove meningiomas: approaches and complications. J Clin Neurosci. 2009;16(9):1168-73. doi:10.1016/j.jocn.2008.12.013

18. Symon L, Olfactory groove and suprasellar meningiomas. In: Krayonbühl H, editor. Advances and technical standards in neurosurgery. Wien: Springer; 1977. p. 67-91.

19. Romani R, Lehecka M, Gaal E, Toninelli S, Celik O, Niemelä M et al. Lateral supraorbital approach applied to olfactory groove meningiomas: experience with 66 consecutive patients. Neurosurgery. 2009;65(1):39-52. doi:10.1227/01.NEU.0000346266.69493.88

20. Turazzi S, Cristofori L, Gambin R, Bricolo A. The pterional approach for the microsurgical removal of olfactory groove meningiomas. Neurosurgery. 1999;45(4):821-6. doi:10.1097/00006123-199910000-00016
21. Ojemann RG. Olfactory groove meningiomas. In: Al-Mefty O, editor. Meningiomas. New York: Raven; 1991. p. 383-93.

22. Hassler W, Zentner J. Pterional approach for surgical treatment of olfactory groove meningiomas. Neurosurgery. 1989;25(6):942-7. doi:10.1227/00006123-198912000-00014

23. Goel A, Muzumdar D, Desai KI. Tuberculum sellae meningioma: a report on management on the basis of a surgical experience with 70 patients. Neurosurgery. 2002;51(6):1358-64.

24. Poppen JL. Operative techniques for removal of olfactory groove and suprasellar meningiomas. Clin Neurosurg. 1964;11:1-7.

25. Al-Mefty O. Tuberculum sellae and olfactory groove meningiomas. In: Sekhar LN, Janecka IP, editors. Surgery of cranial base tumors. New York: Raven; 1993. p. 507-19.

26. Pamir MN, Ozduman K, Belirgen M, Kilic T, Ozek MM. Outcome determinants of pterional surgery for tuberculum sellae meningiomas. Acta Neurochir (Wien). 2005;147(11):1121-30. doi:10.1007/s00701-005-0625-0

27. Bogaev CA, Sekhar LN. Olfactory groove and planum sphenoidale meningiomas. In: Sekhar LN, Fessler RG. Atlas of neurosurgical techniques. New York Brain Thieme; 2006. p. 608-17.

28. Park CK, Jung HW, Yang SY, Seol HJ, Paek SH, Kim DG. Surgically treated tuberculum sellae and diaphragm sellae meningiomas: the importance of short-term visual outcome. Neurosurgery. 2006;59(2):238-43. doi:10.1227/01.NEU.0000223341.08402.C5

29. Bassiouni, H., Asgari, S., Stolke, D.: Olfactory groove meningiomas: functional outcome in a series treated microsurgically. Acta Neurochir (Wien). 2007;149(2):109-21. doi:10.1007/s00701-006-1075-z

30. Romani R, Laakso A, Kangasniemi M, Niemelä M, Hernesniemi J. Lateral supraorbital approach applied to tuberculum sellae meningiomas: experience with 52 consecutive patients. Neurosurgery. 2012;70(6):1504-19. doi:10.1227/NEU.0b013e31824a36e8 